Available online at https://jurnal.stmikroyal.ac.id/index.php/jurdimas

\title{
PELATIHAN MICROSOFT EXCEL BAGI MAHASISWA CALON GURU UNIVERSITAS PENDIDIKAN MANDALIKA
}

\author{
Baiq Rika Ayu Febrilia $^{1^{*}}$, Dwi Utami Setyawati ${ }^{1}$ \\ ${ }^{1}$ Pendidikan Matematika, Universitas Pendidikan Mandalika \\ email: rikafebrilia@ikipmataram.ac.id
}

\begin{abstract}
This community service aims to improve student skills in operating Microsoft Excel. The subjects in this service are final year prospective teacher students of the Faculty of Science, Engineering and Applied (FSTT), Mandalika University of Education. The dedication method used is in the form of training, in which there are two stages carried out in the service, namely the preparation stage of the stage that identifies what problems arise in the subject and the implementation stage of the material delivery to the subject, be it in lectures or direct practice. The results of this community service stated that the beginning of the student meeting had some obstacles in inputting the formula because there was a slight difference between Microsoft Word and Excel. However, after being guided by a team of devotees, the student obstacles were minimized until finally the students were able to use the ru-mus, print charts or diagrams and run the syntax of vlookup and hlookup. So, it can be said that this service goes according to the target of the service team.
\end{abstract}

Keywords: microsoft excel; prospective teacher students; training

\begin{abstract}
Abstrak: Semakin hari teknologi sangatlah dibutuhkan oleh masyarakat, khususnya mahasiswa guna menjalankan kewajibannya dalam mengerjakan tugasnya, sehingga pengabdi membuat pelatihan Microsoft Excel. Hal ini bertujuan agar keterampilan yang dimiliki mahasiswa dalam mengoperasikan Microsoft excel semakin meningkat. Adapun subjek dalam pengabdian ini adalah mahasiswa calon guru tingkat akhir Fakultas Sains, Teknik dan Terapan (FSTT), Universitas Pendidikan Mandalika. Metode pengabdian yang dilakukan adalah dalam bentuk pelatihan, yang mana terdapat dua tahap yang dilakukan dalam pengabdian, yaitu tahap persiapan tahapan yang mengidentifikasi permasalahan apa yang muncul pada subjek serta tahap pelaksanaan tahapan pemberian materi kepada subjek, baik itu secara ceramah ataupun praktik langsung. Hasil dari pengabdian kepada mayarakat ini menyatakan bahwa awal dari pertemuan mahasiswa memilki beberapa kendala dalam menginput rumus karena adanya sedikit perbedaan antara Microsoft Word dan Excel. Akan tetapi, setelah dibimbing oleh tim pengabdi, mahasiswa kendala tersebut berhasil diminimalisir sampai pada akhirnya mahasiswa mampu menggunakan rumus, mencetak grafik atau diagram dan menjalankan sintaks vlookup dan hlookup. Jadi, dapat dikatakan bahwa pengabdian ini berjalan sesuai target dari tim pengabdi.
\end{abstract}

Kata kunci: mahasiswa calon guru; microsoft excel; pelatihan. 
Available online at https://jurnal.stmikroyal.ac.id/index.php/jurdimas

\section{PENDAHULUAN}

Teknologi informasi telah menjadi kebutuhan sehari-hari dalam masyarakat. Dewasa ini, masyarakat malah sudah menjadikan teknologi sebagai teman terdekatnya yang selalu membayangi setiap lini kehidupannya (Wali \& Mukhtar, 2020). Terlebih pada masyarakat yang berstatus mahasiswa, untuk dapat memberikan nilai lebih kepada setiap mahasiswa maka mereka perlu dibekali kemampuan dan keterampilan teknologi yang baik. Nantinya keterampilan ini akan membantu mereka khususnya dalam bidang pekerjaan.

Dalam mengoperasikan perangkat lunak, mahasiswa telah dianggap cukup memiliki kemampuan karena saat mereka berada di bangku Sekolah Menengah Atas (SMA) mereka telah memperoleh ilmu dan pengetahuan tersebut dalam pelajaran Teknologi Informasi dan Komunikasi (TIK). Akan tetapi anggapan ini tidak sesuai dengan kenyataan yang ada. Faktanya, masih banyak mahasiswa yang tidak memahami dengan baik bagaimana mengoperasikan berbagai perangkat lunak dasar seperti Microsoft Excel. Hal ini dimungkinkan terjadi karena pemanfaatan, penggu-naan dan penerapan Microsoft Excel belum maksimal di sekolah (Petro \& Swatan, 2019). Microsoft Excel merupakan salah satu perangkat lunak yang dapat digunakan untuk melaporkan kondisi keuangan seseorang, instansi dan badan usaha lainnya (Mulyani, 2019) dan pengolahan data (Arsi, 2019).

Hasil wawancara dengan beberapa mahasiswa Universitas Pendidikan Mandalika menunjukkan bahwa beberapa diantara mereka memang telah menggunakan Microsoft Excel sejak SMP, ada pula yang mengenal sejak SMA, kuliah bahkan ada yang tidak mengenal sama sekali. Meskipun ada beberapa dari mereka yang telah mengenal dan berinteraksi dengan Microsoft Excel, mereka jarang dan hanya beberapa kali bahkan tidak pernah sama sekali menggunakannya untuk keperluan lain selain untuk mengerjakan tugas yang diberikan guru (Mutia, 2016). Kemampuan yang dimiliki juga sebatas dalam membuat tabel dan menghitung besaran tertentu secara manual, tanpa menggunakan formula yang telah ada pada software tersebut.

Oleh karena kurangnya frekuensi mereka dalam berinteraksi dengan Microsoft Excel, ini membuat mahasiswa tidak memiliki cukup kemampuan dalam membangun logika mereka dalam membuat rumus yang lebih kompleks (Nababan \& Jannah, 2019). Hal ini karena Microsoft Excel juga memiliki bahasa atau sintak tertentu yang membuat rumus bisa dihitung dengan baik. Microsoft Excel juga memiliki beberapa perbedaan dalam menulis jika dibandingkan dengan Microsoft Word (Sari, 2020), sehingga mahasiswa juga perlu memahami dengan baik di mana letak perbedaannya dan bagaimana sintak yang cocok digunakan untuk setiap jenis software yang dipelajari. Lebih jauh, karena beberapa mahasiswa di program studi (prodi) tertentu juga akan mendapatkan materi tertentu yang berkaitan dengan algoritma dan pemrograman, maka dengan tidak terbiasanya mereka mengoperasikan Microsoft Excel akan berimbas kepada ketidakmampuan mahasiswa dalam mengikuti perkuliahan komputer yang lebih tinggi (Rani, 2018). Hal ini juga akan mengakibatkan proses pembelajaran terhambat karena dosen harus menjelaskan kembali dasarnya mengingat $\mathrm{Mi}$ crosoft Excel karena materi ini dibahas secara spesifik pada mata kuliah tertentu di Universitas Pendidikan Mandalika. Di 
Available online at https://jurnal.stmikroyal.ac.id/index.php/jurdimas

sisi lain, setelah mahasiswa lulus dari institusi, mereka juga tidak mampu berkompetisi dengan baik karena Microsoft Excel termasuk perangkat lunak yang harus dikuasai oleh mereka. Oleh karenanya, untuk dapat membuat kualitas mahasiswa semakin membaik, maka perlu adanya pelatihan yang membahas mengenai Microsoft Excel baik dari level dasar hingga menengah.

Permasalahan mitra yang telah diuraikan sebelumnya dapat diantisi-pasi dengan mengadakan pertemuan khusus dalam membahas secara rinci dan mendalam mengenai langkah-langkah dalam mengoperasikan Microsoft Excel. Hal ini karena pada tingkat Sekolah Menengah Atas (SMA) kebanyakan mahasiswa tidak mendapatkan wawasan dan pengetahuan yang cukup untuk bisa menggunakan Microsoft Excel. Diperlukan adanya dukungan berupa pelatihan sehingga nantinya mereka memiliki keterampilan bawaan sebagai bekal memperoleh pekerjaan yang layak dan bersaing dalam mendapatkannya.

\section{METODE}

Program pengabdian dilaksanakan dalam bentuk pelatihan yang tempat penyelenggaraannya di Ruang Laboratorium Komputer Program Studi (Prodi) Pendidikan Matematika Universitas Pendidikan Mandalika. Peserta dari kegiatan workshop adalah mahasiswa Fakultas Sains, Teknik dan Terapan (FSTT) sebanyak 27 orang. Dalam pelak-sanannya, kegiatan ini melalui dua tahapan, yaitu tahap persiapan dan pelaksanaan. Penjelasan singkat mengenai masing-masing tahapan adalah sebagai berikut.

\section{Tahap Persiapan}

Penyusunan rencana kegiatan pelatihan dilakukan dengan melibatkan mitra secara langsung. Beberapa sampel mahasiswa diwawancarai dan diajak untuk berdiskusi secara langsung untuk mengetahui kesulitan dan masalah mereka dalam mengoperasikan Microsoft Excel, sehingga dapat ditentukan materi apa yang sebaiknya disampaikan. Bersamasama dengan mahasiswa, pelaksana pengabdian kemudian menentukan hari penyelenggaraan dan lokasi pelatihan yang memungkinkan.

\section{Tahap Pelaksanaan}

Hasil diskusi bersama mahasiswa memberikan kepastian terselenggaranya tiga hari pelatihan mulai tanggal 27 hingga 29 Mei 2019. Selama kegiatan workshop, mahasiswa diperkenalkan tools dasar Microsoft Excel, beberapa rumus sederhana seperti rumus aritmatika, rumus logika, vlookup dan hlookup serta langkah dalam membuat grafik atau diagram.

\section{PEMBAHASAN}

Mahasiswa yang mengikuti pelatihan sebagian besar merupakan mahasiswa tahun terakhir yang memang dituntut untuk memiliki keterampilan tertentu sebelum lulus dari universitas. Kebanyakan dari mereka berjenis kelamin perempuan, namun tetap ada mahasiswa laki-laki yang juga ikut serta.

Secara umum, respon mahasiswa terhadap kegiatan ini sangat baik. Hal ini dapat dilihat dari banyaknya mahasiswa yang mendaftar via formulir google yang disebarkan, meskipun pada saat kegiatan terdapat beberapa mahasiswa yang tidak dapat hadir karena beberapa faktor. 
Available online at https://jurnal.stmikroyal.ac.id/index.php/jurdimas

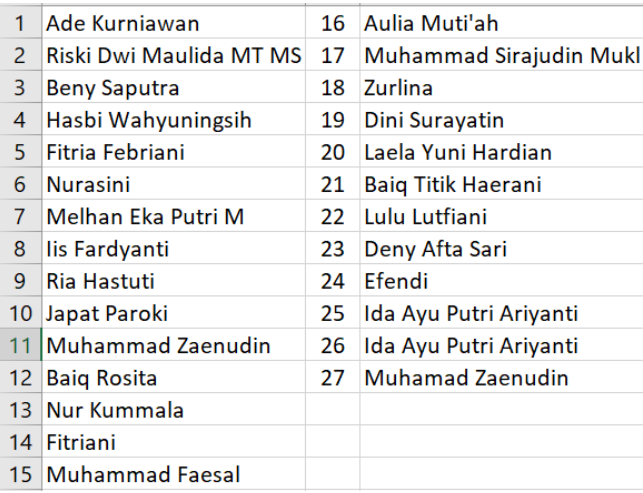

\section{Gambar 1. Daftar Nama Peserta}

Pada hari pertama, narasumber memberikan perkenalan Microsoft Excel secara umum kepada semua peserta termasuk berbagai macam manfaat Microsoft Excel serta prospek pekerjaan yang membutuhkan kemampuan dalam mengoperasi-kannya. Mahasiswa juga diminta untuk memperhatikan perbedaan halaman pada Microsoft Word dan Excel termasuk bagaimana aturan dalam menulisnya seperti penggunaan tombol enter, sim dan berbagai perbedaan yang mungkin muncul pada kedua perangkat lunak ini. Penjelasan dilanjutkan dengan perkenalan isi dari toolbar yang ada kemudian peserta diminta untuk mencoba menggunakan toolbar yang sudah dipelajari. Pada Gambar 2 merupakan dokumentasi dari kegiatan pelatihan.

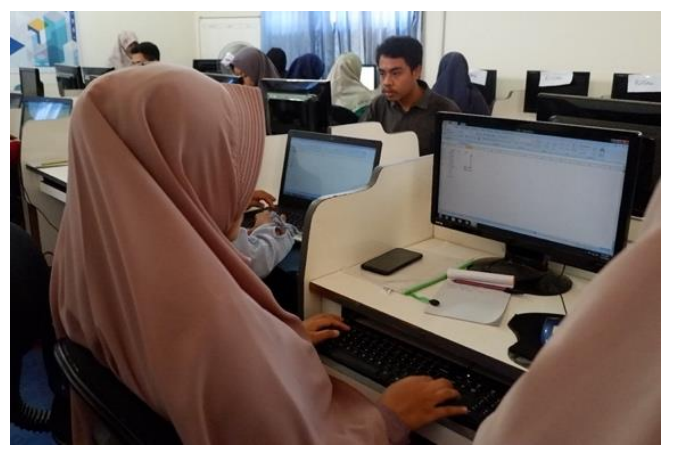

Gambar 2. Peserta Pelatihan
Kegiatan pelatihan tidak hanya satu arah, yaitu peserta hanya mendengarkan fasilitator dalam berbicara, tetapi peserta juga diminta untuk mengaplikasikan secara langsung tools yang dijelaskan. Salah satu fitur yang dijelaskan adalah menu bar. Pada bagian ini peserta diminta untuk melihat setiap komponen dalam setiap menu pada Microsoft Excel dan mencoba beberapa pilihan di dalamnya. Pada Gambar 2 nampak bahwa mahasiswa sedang mencoba mempraktekkan penjelasan yang diberikan tim, termasuk langkah yang dilakukan dalam membuat grafik atau diagram (Gambar 3).

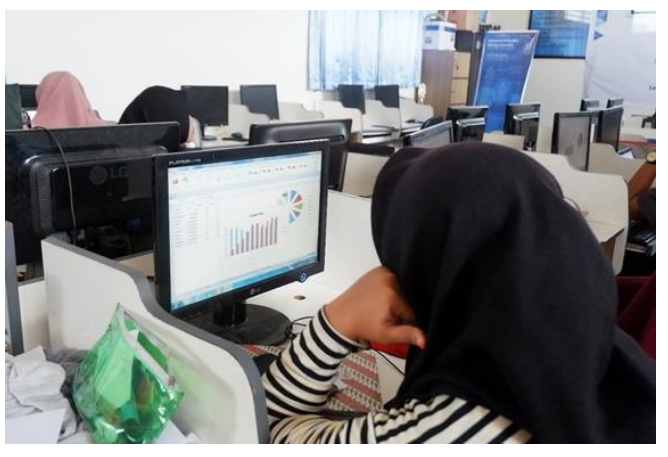

Gambar 3. Peserta Membuat Grafik

Saat memperkenalkan rumusrumus dasar dan bagaimana penggunaannya, fasilitator juga melakukan demonstrasi sekaligus meminta peserta untuk mencoba menerapkan rumus tersebut sendiri. Peserta sangat merespon dengan baik kegiatan ini karena menurut mereka rumus-rumus yang diberikan sebagian besar belum pernah dipelajari, dan rumus ini juga akan sangat bermanfaat bagi peserta kedepannya. Setelah melatih pemahamannya dalam rumus-rumus yang diperkenalkan, peserta kemudian diberikan soal berupa data yang harus peserta tentukan nilai-nilai tertentu dalam data tersebut dengan menggunakan rumus-rumus yang telah diberikan. 
Available online at https://jurnal.stmikroyal.ac.id/index.php/jurdimas

Selama kegiatan berlangsung, masih banyak ditemukan mahasiswa yang belum terbiasa dalam berinteraksi dengan Microsoft Excel karena pengetahuan dasar mereka belum cukup. Sebagai contoh, terdapat beberapa ketentuan dalam menginput rumus yang terlupakan oleh mahasiswa termasuk lupa memberikan tanda kurung tutup yang jumlahnya sama dengan kurung buka dan sebagainya. Di sini fasilitator perlu memberikan perhatian lebih agar mahasiswa dapat mengikuti alur kegiatan dengan baik. Gambar 4 merupakan salah satu contoh hasil pekerjaan peserta dalam mengikuti pelatihan.

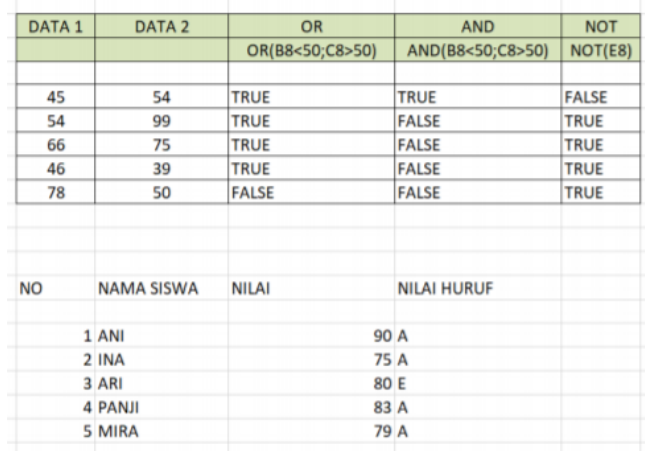

Gambar 4. Hasil Pekerjaan Peserta dalam bentuk tabel.

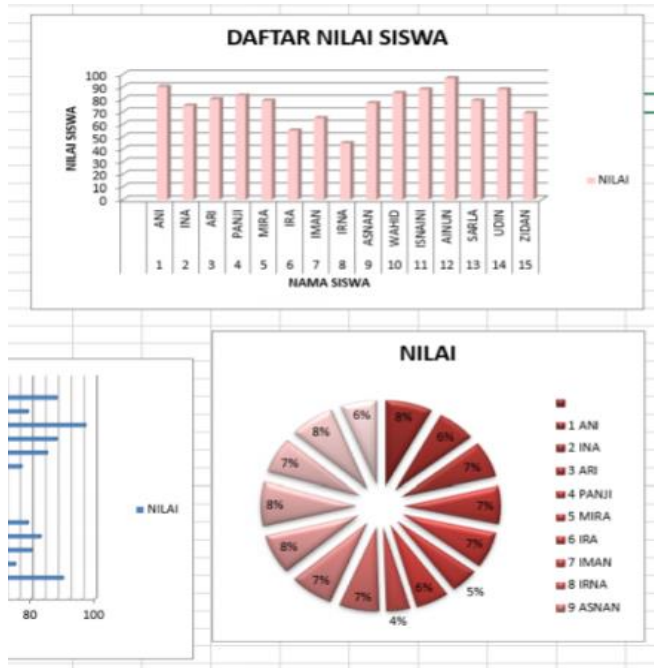

Gambar 5. Hasil Pekerjaan Peserta dalam bentuk grafik

\begin{tabular}{|l|l|l|l|}
\hline \multicolumn{1}{|c|}{ NAMA } & \multicolumn{1}{c|}{ KODE } & \multicolumn{1}{c|}{ TYPE } & \multicolumn{1}{c|}{ TYPE } \\
\hline PENYEWA & KAMAR & \multicolumn{1}{c|}{ KAMAR } & \multicolumn{1}{c|}{ KAMAR } \\
\hline & & \multicolumn{1}{|c|}{ (VLOOKUP) } & (HLOOKUP) \\
\hline KURNIAWAN & D & DOUBLE & DOUBLE \\
\hline BAGUS & D & DOUBLE & DOUBLE \\
\hline EKA & F & FAMILY & FAMILY \\
\hline KURNIA & S & SINGLE & SINGLE \\
\hline BUDI & D & DOUBLE & DOUBLE \\
\hline RANGGA & F & FAMILY & FAMILY \\
\hline SUCI & S & SINGLE & SINGLE \\
\hline
\end{tabular}

Gambar 6. Hasil Pekerjaan Peserta

Berdasarkan hasil yang telah dicapai selama kegiatan berlangsung dan respon mahasiswa yang disampaikan pada akhir kegiatan maka dapat disimpulkan bahwa program pengabdian cukup berhasil dalam menambah wawasan, pengetahuan dan keterampilan siswa.

Berikut doku-mentasi gambar antara pemateri dan peserta pada pelatihan Microsoft excel

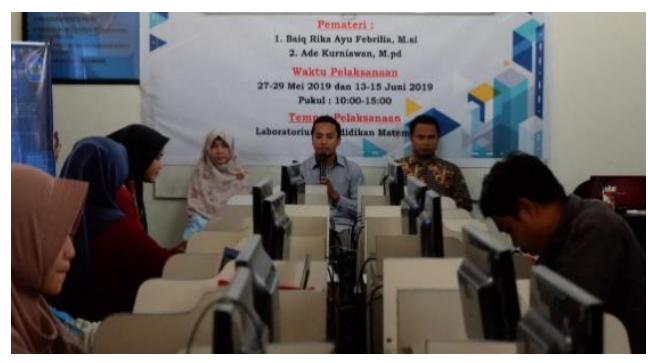

Gambar 7. Tutor dan Peserta

\section{SIMPULAN}

Berdasarkan pemaparan hasil program pelatihan maka dapat disimpulkan bahwa kegiatan telah dilaksanakan dengan baik dan mendapatkan respon yang baik pula dari mahasiswa. Kegiatan pelatihan ini berhasil membuat mahasiswa berlatih dalam mengoperasikan Microsoft Excel dengan memanfaatkan fitur dan rumus dasar yang telah disediakan. 
Available online at https://jurnal.stmikroyal.ac.id/index.php/jurdimas

\section{DAFTAR PUSTAKA}

Arsi, P., Suliswaningsih, S., Pambudi, A. S., \& Maisa, W. (2019). Peningkatan Kualitas Sdm Dengan Pemanfaatan Iptek Melalui Pelatihan Komputer Dasar Dan Internet Pada Anggota Polsek Kedungbanteng. Jurnal Abdimas BSI: Jurnal Pengabdian Kepada Masyarakat, 2(2), 191-196. https://doi.org/10.31294/jabdimas.v $2 \mathrm{i} 2.4244$

Mulyani, Y. S., Wibisono, T., Alawiyah, T., \& Warnilah, A. I. (2019). Pelatihan Komputer Dasar Untuk Mendukung Proses Kegiatan Belajar Mengajar (Kbm) Bagi Guru-Guru $\mathrm{Ra} / \mathrm{Tpq} / \mathrm{Dta}$ Al-Ishlaah Kota Tasikmalaya. Jurnal Abdimas BSI: Jurnal Pengabdian Kepada Masyarakat, 2(2), 234-240. https://doi.org/10.31294/jabdimas.v $2 \mathrm{i} 2.5768$

Mutia, I. (2016). Penerapan Teknologi Komputasi Awan ( Cloud Computing ) Untuk Pembelajaran Mahasiswa di Perguruan Tinggi. Jurnal LPPM Unindra, 9(3), 283292.

Nababan, A. A., \& Jannah, M. (2019). Pelatihan Microsoft Office Bagi Mahasiswa Di Universitas Medan Area. TRIDARMA, 2(2), 67-73.
Petro, S., \& Swatan, K. H. (2019). Pelatihan Microsoft Excel Sebagai Penunjang Ketrampilan Hard Skill Bagi Siswa Pada SMK Ypsei Palangka Raya. Jurnal Abdimas BSI: Jurnal Pengabdian Kepada Masyarakat, 2(2), 280-286. https://doi.org/10.31294/jabdimas.v 2i2.6011

Rani, S., Punajii, S., \& Zainul, A. (2018). Persepsi Mahasiswa Teknologi Pendidikan Universitas Negeri Malang tentang Pentingnya Keterampilan Dasar Mengajar terhadap Kompetensi Lulusan Teknologi Pendidikan. Persepsi Mahasiswa Teknologi Pendidikan Universitas Negeri Malang Tentang Pentingnya Keterampilan Dasar Mengajar Terhadap Kompetensi Lulusan Teknologi Pendidikan, 1(4), 263-272.

Sari, R., Fitriyani, A., \& Prabandari, R. D. (2020). Optimalisasi Penggunaan MS . Word dan MS . Excel Pada Siswa SMP PGRI Astra Insani Bekasi. Jurnal Sains Teknologi Dalam Pemberdaaan Masyarakat, 1(1), 39-48.

Wali, M., \& Mukhtar. (2020). Pelatihan Microsoft Excel 2013 Dalam Rangka Membentuk Tenaga Pengajar Yang Profesional. TRIDARMA, 3(1), 31-34. 